\title{
Advancing electronic monitoring in Scotland: Understanding the influences of localism and professional ideologies
}

Hannah Graham, University of Stirling, $U K^{1}$

Gill McIvor, University of Stirling, $U K^{2}$

\section{Pre-print version - Citation}

Graham, H., \& McIvor, G. (2017) 'Advancing electronic monitoring in Scotland: Understanding the influences of localism and professional ideologies' European Journal of Probation 9(1): pages 62-79. DOI: 10.1177/2066220317697659.

Available online at: http://journals.sagepub.com/doi/full/10.1177/2066220317697659

\begin{abstract}
Scotland has one of the highest prison population rates in Western Europe, coinciding with a recent growth in interest in electronic monitoring (EM) as a potential mechanism for diversion and decarceration. Scotland also has a relatively sophisticated suite of community sanctions and measures - from which court-imposed and prison-imposed EM orders have, for 15 years, been largely kept separate, until now. This article analyses the perspectives of Scottish practitioners and decision-makers regarding current stand-alone uses of electronic monitoring, canvassing relevant Scottish jurisdictional findings from within a larger European comparative research project. It reveals localised, institutional and professional differences in the Scottish criminal justice field. Our analysis demonstrates that Scottish practitioners want more integration in principle, but forewarns that the extent of their support may depend on how and by whom this is done in practice.
\end{abstract}

\section{Keywords}

Electronic monitoring, tagging, Scotland, localism, professional ideologies, criminal justice work

\footnotetext{
${ }^{1}$ Dr Hannah Graham is a Lecturer in Criminology in the Scottish Centre for Crime and Justice Research (SCCJR) at the University of Stirling, UK. Email h.m.graham@stir.ac.uk

2 Prof Gill McIvor is a Professor of Criminology in the Scottish Centre for Crime and Justice Research (SCCJR) at the University of Stirling, UK. Email gillian.mcivor@stir.ac.uk
} 


\section{Introduction}

Historically, prominent debates about electronic monitoring (EM) have tended to foreground a focus on EM technologies and modalities, scrutinising their efficacy to help realise certain penal objectives. The most common questions, in Western neoliberal jurisdictions at least, have tended to revolve around the effectiveness of a particular use of EM in seeking to reduce recidivism rates, and its utility as an 'alternative' to prison both to increase rates of diversion and decarceration and to decrease incarceration rates and costs. As highlighted by colleagues in this Issue (see Dünkel et al., this Issue), rates of incarceration and the conditions of incarceration (including the risk or the reality of overcrowding), can weigh on the direction of penal policymaking and decision-making in different European jurisdictions, and we would include Scotland in this.

Yet, a historically narrow focus on understanding electronic monitoring technologies and modalities almost exclusively as means to these particular ends run the risk of such discussions becoming de-contextualised and instrumental where they are not accompanied by commensurate understanding of the pragmatic realities, actors and dynamics of the field in which they occur. Electronic monitoring products and practices are nested in professional, institutional, local and jurisdictional cultures, reflecting a particular moment in time. More attention has been devoted to whom EM is used with, than it has been to who uses it and how they work with others in doing so. Yet, internationally, some level of involvement with or use of electronic monitoring is an increasingly common feature of court work, probation work and prison work. A few scholars have considered electronic monitoring and surveillance work with specific regard for the perspectives of those who undertake it, often focused on field officers in private companies (for example, Paterson, 2007; Hucklesby, 2011; Smith, 2012). Others have considered professional ideologies, inter-professional relations and cultures in probation work and community justice (for example, Halliday et al., 2009; Rudes et al., 2014; Graham, 2016). Yet there remains a pressing need for more empirical and theoretical scholarship examining the interfaces of these things, including resultant confluences and conflicts in the field, predicated on a clear understanding of how these may affect pursuit of integration.

This article centres on the Scottish jurisdictional research findings, which form part of a larger European comparative research project about electronic monitoring as an alternative to custody in the EU. It encompasses a review of recent policy developments, recognising that the historical use of stand-alone EM is set to change in pursuit of integration. Discussions then concentrate on how diverse Scottish participants in this study perceive and currently use 'stand-alone' electronic monitoring, and their outlooks on future uses. The participants in this research are practitioners and decision-makers, making sense of EM in 
the bounded context of their work and field of work. Significant localised, institutional and professional differences emerge from their qualitative accounts. These differences are likely to bear influence on efforts to advance the uses of electronic monitoring to become more integrated and flexible in the future.

\section{The study}

This article focuses on one area of thematic findings within the research in Scotland participant perspectives on 'stand-alone' uses (the present status quo) compared to the prospect of integrated uses of EM with other community sanctions and measures. However, the Scottish findings are much wider, and form part of a larger European comparative research project involving four other jurisdictions: England \& Wales, Belgium, Germany and the Netherlands. This cross-national study has been commissioned and funded by the European Commission ${ }^{1}$, and is the first of its kind in Europe to empirically and comparatively investigate the uses of electronic monitoring in such depth. Across the five jurisdictions, a combined total of 75 days of ethnographic observation and over 190 interviews were conducted by the research partners, in combination with using other forms of evidence and secondary data (see Hucklesby, Beyens, Boone, Dünkel, McIvor and Graham, , 2016a, 2016b).

Within Scotland, the research findings and some of the recommendations outlined here are based on analysis of 30 interviews we conducted in 2015 with various criminal justice actors and 53 hours of ethnographic observation of the tagging process both at the National Electronic Monitoring Centre outside Glasgow, and through accompanying EM field officers into monitored people's homes at night. The primary data is supported by evidence from other secondary sources such as statistics, a literature review and policy review (see Graham and McIvor, 2015). The interview sample includes four sheriffs, six criminal justice social workers, five Scottish Prison Service staff, a representative of Police Scotland, a member of the Parole Board for Scotland, nine G4S electronic monitoring staff, two Scottish Government Justice policymakers, and two members of staff from a third sector representative organisation. Research interviews were conducted with participants in places where EM is used regularly, as well as in places where it is not, to explore reasons for its variation in use. These places have not been publicly identified to protect participant anonymity in a small jurisdiction. The sections that follow identify common narratives emerging from the data, with indications of how these have the potential to influence future uses of EM in Scotland. 
The sample is made up of practitioners and decision-makers, and does not include monitored people. A sample size of 30 practitioner interviews per country was a target set in agreement with the other research partners at the outset of this project. It is acknowledged that this jurisdictional sample is relatively small - albeit one that is, arguably, appropriate in the context of a small jurisdiction such as Scotland, in combination with other sources of evidence. Nonetheless, some of the themes and findings raised here should be understood as emergent, and related discussions as exploratory.

With regard to extant empirical literature about EM in Scotland, the analytical insights of Mike Nellis (2006, 2007, 2009, 2014, 2015, 2016a, 2016b; Mair and Nellis, 2013), a Scotlandbased scholar with internationally recognised expertise in electronic monitoring and active involvement in shaping Scottish EM policymaking, stand out above the rest as offering one of the most cogent accounts within what remains a small body of Scottish EM literature. His insights and those of a few relevant others are interwoven and built on where apt in the discussions that follow. Additionally, the research presented here is premised on a separate but related in-depth international evidence review (Graham and McIvor, 2015) commissioned by the Scottish Government and conducted by the article authors during the same period of time as this European study.

\section{Electronic monitoring in Scotland, 2002-2016: A bounded overview}

Electronic monitoring is available at various points in the criminal justice process in Scotland. This section encompasses a brief overview of the infrastructure and key features of how EM has been used in stand-alone form since its inception nationally in 2002, and discussion of recent policy consultations and processes which signal shifts in pursuit of integration.

\section{Electronic monitoring modalities and technologies in Scotland}

Electronic monitoring has existed in Scotland for over 15 years, and has relied on the use of one EM technology: radio frequency (RF) tagging in combination with curfew restrictions, often to a home for a curfew period of up to 12 hours. EM is used in its own right with adults and young adults as a stand-alone community penalty called a Restriction of Liberty Order, as well as stand-alone uses with prisoners on early release on licence with a Home Detention Curfew. It is used in a small number of cases with parolees as well as, more recently, in the event of breach of a Community Payback Order (the principal supervisory community penalty in Scotland to which a range of specific requirements can be attached). EM is rarely used in the case of a Drug Treatment and Testing Order even though the potential exists for it to be used in this way. 
A range of stakeholders are involved in decision-making and implementation of electronic monitoring in Scotland. Electronic monitoring legislation and policy are set nationally by the Scottish Government. The systemic organisation of electronic monitoring in Scotland is similar to the Anglo-Welsh approach of privatised EM service provision, which revolves around tagging technology installation and de-installation, monitoring and reporting to statutory authorities. The current contractual framework involves close oversight between the Scottish Government Justice Department (Community Justice Division) and the national private service provider, which is currently G4S, with 'tight' accountability 'via real-time access to the contractor's data on all tagged offenders, monthly performance audits and regular meetings with managers' (Nellis, 2016a: 184). A detailed description of the electronic monitoring process is available in our Scottish jurisdictional research report (McIvor and Graham, 2016b).

Despite its use for more than fifteen years, EM has remained a small scale feature of punishment in Scotland. In the 12 month period from 1 January - 31 December 2015, a total of 1,806 new Restriction of Liberty Orders (stand-alone EM orders) were imposed, most commonly for a period of 3 or 4 months (G4S, 2016). Within the custodial estate, the use of electronically monitored early release from prison on a Home Detention Curfew (HDC) licence remains modest. In mid-September 2016, Scottish Prison Service (2016) statistics indicate that there were a total of 7,674 people in Scottish prisons, and 284 prisoners on electronically monitored Home Detention Curfew (HDC), amounting to a prison population total of 7,955. EM order completion rates for court-imposed and prison-imposed orders are relatively high and stable, with approximately 8 out of $10 \mathrm{EM}$ orders being completed in Scotland in 2015 (see G4S, 2016).

A small amount of evaluation research has been conducted about the effectiveness of specific EM modalities and pilot schemes (for example, see Armstrong et al., 2011; Barry et al., 2007). However, one overarching challenge which has inhibited more advanced conclusions being drawn in this research is the lack of available data to analyse the effectiveness of electronic monitoring in Scotland, an issue encountered in each of the other jurisdictions in this study. The quantitative information that is available is descriptive and somewhat rudimentary in what can be inferred from it.

Figure 1 illustrates a recent trend (since 2011-2012) for community sentences such as Restriction of Liberty Orders (EM) and Community Payback Orders to be associated with lower reconviction rates compared to those discharged from custody. 
Figure 1: Trends in Reconviction Rates (\%) by Index Disposal in Scotland, 2002-03 to 2012$13^{3}$

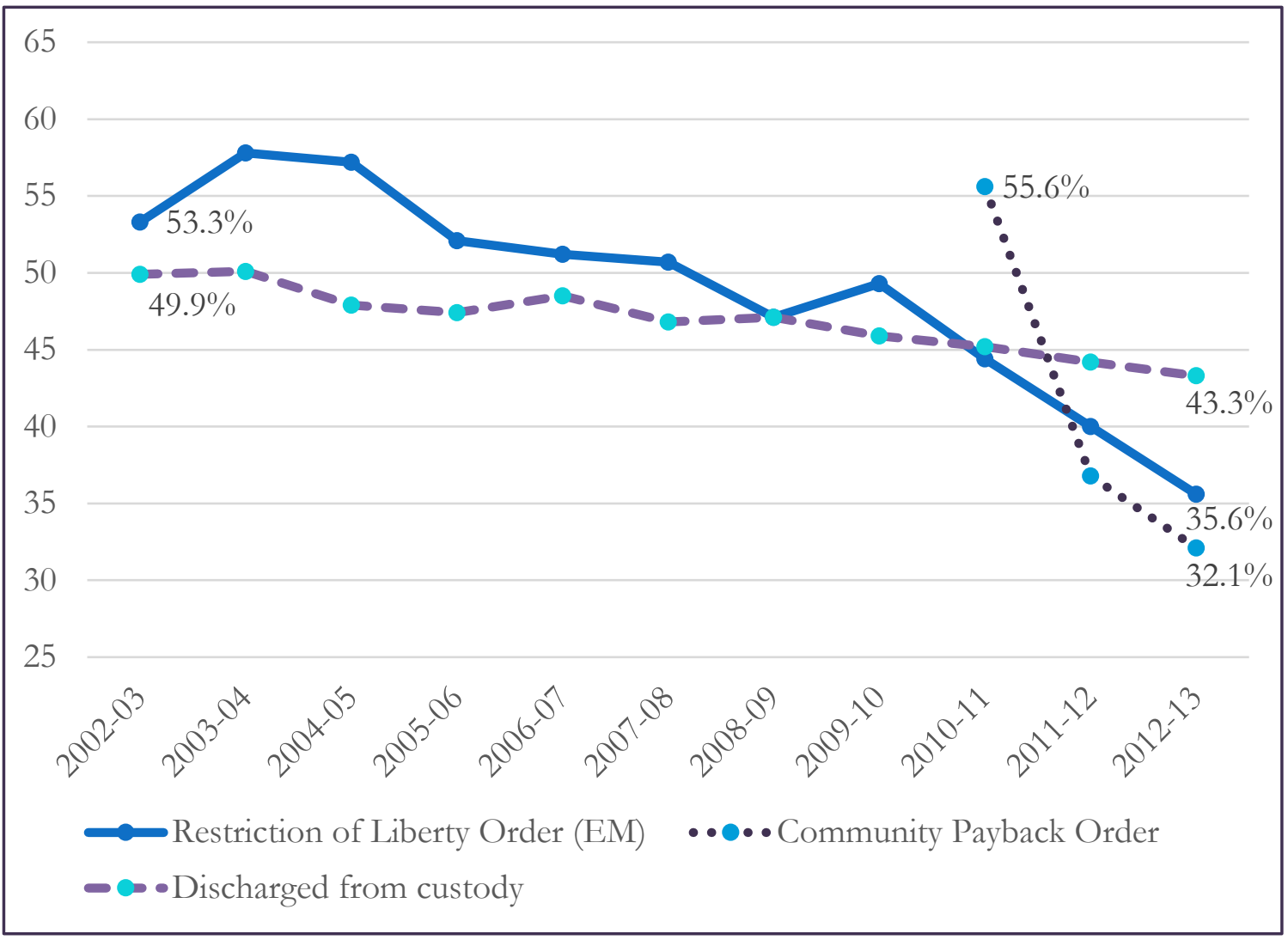

Source: Adapted from the Scottish Government (2015).

Even despite researching EM in Scotland in some depth, there are limited claims we can make about its effectiveness in achieving penal purposes where there is insufficient data about the 'how' and 'why' behind figures and trends, including that which is illustrated in Figure 1. As argued from the outset, any trends and changes need to be contextualised.

\section{3-2016: Policy consultations and consensus-building in a season of change}

This two year research project has taken place in a season of change, and there are background features worth acknowledging for how they frame some of the themes and empirical contributions of this study. Our summary here is not entirely dispassionate because of the extent of our involvement in recommending changes subsequently taken up by

\footnotetext{
${ }^{3}$ Note: The reconviction rate in Figure 1 is based on a 1 year follow-up period. Restriction of Liberty Orders started in 2002, and Community Payback Orders started in 2011.
} 
government policymakers, even during the time this article has been written (see Graham and McIvor, 2015, 2016; McIvor and Graham, 2016a, 2016b; Scottish Government, 2016a).

In the European context, it is noteworthy that this comparative research project includes Scotland as a separate jurisdiction to England and Wales, given that the EU typically commissions grants at the level of EU Member States. The domestic, regional and continental contours of this 'season of change' have become more pronounced in the two year period of data collection and analysis for this research (mid-2014 to mid-2016), with macro social and political processes bearing influence. In these two years, Scots have been to the ballot boxes to vote four times: two consecutive election years (Scottish Parliament and Westminster Parliament) and, significantly, being bracketed by two referendums (the 2014 Scottish independence referendum and the 2016 UK referendum on EU membership, or 'Brexit' as it is now commonly known). Overtures about penal policy have been made in this political atmosphere of uncertainty. An impetus to advance electronic monitoring has featured in Parliamentary party election manifestos in Scotland across the political spectrum, from the Scottish Conservatives to the SNP. A sense of policymaking at a crossroads has underscored discussions of an increasingly prominent question - will Scotland emulate Anglo-Welsh developments or pursue a more European approach? This question has been further compounded by a level of vicarious learning from some recent issues, scandals, and the failure of planned procurement and policy reforms south of the border in relation to Anglo-Welsh uses of EM and their recent approach to probation and privatisation more broadly (see Hucklesby and Holdsworth, 2016; Nellis, 2016c).

Within the domestic context of Scotland, we find ourselves in the midst of a significant season of change, including the overall redesign of Community Justice as well as a detailed process of national consultation specifically devoted to EM. These things have been framed by various different actors, not least by politicians and policymakers in the Scottish Government, for how they occur against the backdrop of (and seek to redress) Scotland having one of the highest prison population rates in Western Europe. The most recent estimate of the Scottish prison population rate is 143 per 100,000 of national population (World Prison Population Brief, 2016). The enduring comparatively high use of custodial sentencing by the Scottish judiciary has been a focal point in policy discussions and penal reform efforts in recent years, where narratives about EM appear to be increasingly subsumed or associated with narratives about more 'robust' community sentences (for example, Scottish Government 2013; Matheson, 2015).

In the autumn of 2013, the Scottish Government (2013) published a consultation on the potential development of electronic monitoring to better take advantage of advances in technology, in particular the availability of improved GPS tagging technology. At a general 
level, the consultation sought the submission of views from any interested parties on how electronic monitoring could be better integrated with other supervision and support services, how the system of breach and enforcement could be developed, and identification of the barriers to increasing the rates of use of EM as an alternative to imprisonment. Views were also sought on the use and development of new EM technologies, including GPS and remote alcohol monitoring, on its use by police for other purposes, and the potential development of an electronic reminder service. Fawcett, Costley and Granville (2014) collated and analysed the consultation responses, with numerous themes and issues emerging that were also raised by participants in our study. They found moderate support among respondents for integration of EM service provision to work more closely with criminal justice social workers, as well as the third sector. Consultation respondents also tended to emphasise the need for a greater orientation towards and opportunities for rehabilitation, signalling a desire to move away from stand-alone uses of EM. Following the formal consultation period, in 2014, the Scottish Government established an expert Electronic Monitoring Working Group to discuss, consult and make recommendations to Scottish Ministers about future EM policy and practice reforms.

In addition to the national electronic monitoring consultation in 2013, the Scottish Government held another consultation in 2015 on proposals to strengthen the existing presumption against short periods of imprisonment, seeking responses (of which 63 were received) about whether the current presumption against three month custodial sentences should be increased to a presumption against up to six month or twelve month custodial sentences. This comprised an unambiguous critical stance about the Scottish judicial tendency to send disproportionately high numbers of people to prison for short periods of time, on remand or under sentence. Platts and Waterton's (2016) analysis of this round of consultation responses suggest that the perspectives of numerous respondents largely mirrored the perspectives of numerous participants in this research, stressing the importance of a whole of system strategic approach to community justice, greater partnership working, and support for greater use of EM as an alternative to custody.

In early October 2016, after a two year process of expert group meetings and further consultative activities, the Electronic Monitoring Working Group (2016) report with recommendations to Scottish Ministers was released. It referenced the influence of this research and associated recommendations (Graham and McIvor, 2015; McIvor and Graham, 2016a, 2016b). Cabinet Secretary for Justice Michael Matheson announced that he had accepted all of the Working Group's recommendations and unveiled a raft of Scottish Government (2016a) plans to radically change and expand how EM will be used in Scotland. Integration features centrally in these proposals, which also include: the introduction of GPS 
tagging and tracking technology and transdermal alcohol monitoring tagging technology; the introduction of the option of supervision involving criminal justice social workers; and greater exploration of uses of EM as an alternative to remand, as an alternative to short custodial sentences, as well as more use within the custodial estate to support reintegrative activities. Furthermore, in 2016, the Scottish Government established a new Electronic Monitoring Unit (EMU) within the headquarters of the Community Justice Division, responsible for overseeing EM practice and policy development, including the implementation of some of these proposals.

Overall, there has been a significant amount of positive momentum surrounding the national consultation and recent announcement of plans and reforms as indicative of a collective desire to use EM more strategically. How this is done and what this might look like are the subject of rich and reflexive narratives from different Scottish practitioners, with some ideas widely supported and others contested. The following section complements and builds on this policy and political overview by exploring research participants' perspectives and findings.

\section{Stand-alone EM in Scotland: Simple, standardised, stable - for some}

There are complexities in aptly characterising 'a Scottish approach' to electronic monitoring, for reasons which will be expounded shortly. Nonetheless, from 2002 to 2016, the national picture of the uses of EM in Scotland can broadly be understood as relatively simple, standardised, stable and small in scale. To summarise, these characteristics are evident in systemic and normative features such as:

- Using one EM technology: radio frequency tagging and curfew restrictions have been the only available technology for over fifteen years since the inception of EM.

- Using one private EM services provider (at a time) with a national contract for service delivery.

- Using stand-alone electronic monitoring, with no integrated supervision or supports in the vast majority of cases, meaning very little practitioner involvement except for field officers to fit and check technology and investigate violations.

- Using standardised regimes: the Scottish judiciary and Scottish prisons tend to impose standardised curfew regimes in most cases, for example, a person is restricted to their home from 19:00 to 7:00, 7 nights a week.

- Using electronically monitored orders on a small scale, relative to the larger population of people in prison and serving community sentences without EM. 
The implementation of a stand-alone electronically monitored order once it has been made by an authorising agency (a court, prison or the Parole Board) is moderately routinised, which is due in part to the way in which EM service provision is contracted and overseen. In its current form, stand-alone EM primarily serves the purpose of restriction of liberty as a retributive form of punishment.

However, in defining the Scottish approach to date as 'simple, standardised and stable', we simultaneously wish to problematise this depiction by exploring the contrasting professional relations and institutional contexts which precede whether an EM order is imposed so as to demonstrate that it is routinely these things for some, and practitioners and decision-makers are implicated in affecting where and with whom EM is (or is not) imposed.

\section{The Influences of Localism and Professional Ideologies on Sentencing and Uses of Stand-Alone Electronic Monitoring}

For the sake of brevity, this article predominantly focuses on the perspectives and practices of the judiciary, in this case sheriffs (the Scottish equivalent of magistrates), and criminal justice social workers (the Scottish equivalent of probation officers) as key actors in sentencing and community justice. However, the perspectives of other types of practitioner participants are interwoven where they illuminate the responses of these actors.

To contextualise the themes and findings raised here, there is a tradition of law and criminology academics describing the Scottish judiciary as a 'strongly independent judiciary' (McAra, 2008: 482). In her research, Jamieson (2013) aptly characterises the notion of judicial independence as the 'master narrative' of the Scottish judiciary, implicitly suggesting this is a dominant discourse they are aware of and contribute to. In contrast to other places where judicial decision-making is more structured by jurisdiction-wide thresholds or parameters, the Scottish judiciary have shown some interest in giving consideration to sentencing guidance, but have resisted the use of sentencing guidelines which might obligate more structured and consistent sentencing decisions across the country (Millie, Tombs and Hough, 2007). Tombs and Jagger (2006: 806, 808) characterise the Scottish judiciary as having 'a great deal of discretion in sentencing', with their research findings showing that judicial discourses and sentencing decisions tend to 'focus on the offender, rather than the offence,' leading to 'individualised notions of justice' and significant variation in whether a custodial or a community sentence is imposed, depending on who imposes it and on whom.

This is where a few seemingly paradoxical characteristics and patterns can be discerned. As an occupational group, there is a coherent narrative of hegemony surrounding the Scottish 
judiciary. Yet, within this occupational group, there is a well-established narrative of localised and individualised diversity and variability in decision-making about sentencing and the imposition of EM. Finally, one of the other research findings is that, once sheriffs decide to impose an electronically monitored order, the majority of them choose simple, standardised and strict regimes in its implementation. In other words, they have a high level of power and authority; they do not exercise this consistently relative to one another in their sentencing decisions, but for those who do choose EM, they do the same as their peers across the country in choosing stock-standard versions of it. There is a great variability in whether it gets used, and with whom it gets used, but once it does, there is a lack of creativity and flexibility in how it is used. Some of these paradoxical characteristics warrant further examination.

Differences in sentencing among the Scottish judiciary, particularly among sheriffs, have been well documented and analysed by others (see Hutton and Tata, 1995; Tata et al., 2008). With regards to their use of electronically monitored orders, there continue to be 'marked regional variations' in the rates at which Scottish sheriffs impose Restriction of Liberty Orders (the main stand-alone EM community sentence) (Mair and Nellis, 2013: 77). There is statistical evidence that some sheriffs and courts use these orders frequently, whereas others use them rarely (for more, see McIvor and Graham, 2016b; G4S, 2016). The geographic and localised differences cannot be explained solely on the basis of differences in local area population or annual court workload in criminal proceedings. In 2015, the rate of Restriction of Liberty Orders imposed by sheriffs in Glasgow was 256 per cent higher than that of their Edinburgh counterparts, with 314 imposed in Glasgow compared to 88 in Edinburgh (G4S, 2016). Some courts have experienced distinct rises or reductions in the use of EM orders, with patterns which can sometimes be traced to the influence of an individual sentencer moving into or out of that court area, or instances where an individual sheriff or sheriff court begin to meet with and/or work more frequently in communication with the private EM services provider. One participant describes Scottish sheriffs as 'an autonomous bunch' who 'do things differently' from one another, pointing out that 'England has more in terms of sentencing guidelines than Scotland has' (Interview 2, Police Scotland). Another participant is more forthright in their explanation:

"I think it's a bit all over the place [laughs]. I've spoken to some sheriffs who say "yes absolutely direct alternative to custody", other people saying "well don't tell me it's a direct alternative to custody because you are then de facto telling me how to sentence." I have another sheriff saying "I'll use it as a sentence in its own right" and I've had a couple of sheriffs saying "well I just use it as an alternative to a fine because I know they'll not pay their fine." So even within the sheriffs as a group, there's a range of views regarding how it should be used and who should use it." (Interview 11, G4S staff).

Sheriffs themselves acknowledge their individual differences in sentencing and uses of EM. Some of them are clear that they like EM and use it regularly, and others are more hesitant 
or critical of it. In one or two interviews, sheriffs asked the researcher which modalities EM could be used within, and which EM technologies were available in Scotland, suggesting they not only use it infrequently, but do not necessarily know very much about it. In contrast, one sheriff states 'I'm a fan of Restriction of Liberty Orders and sometimes I use it in a punitive way as an alternative for sending people to jail'; however, they described social workers as 'hating' EM, partly 'because it is privatised', and so 'they virtually never recommend it' (Interview 18, sheriff). When asked if there is consensus between sheriffs and courts regarding why electronically monitored sentences are imposed, another sheriff categorically answered 'no', indicating their view that EM 'isn't really aimed toward rehabilitation at all. Deterrence, maybe?' (Interview 19, sheriff). A sheriff, who indicates that they like EM, speaks of their own sense of agency in using it:

"I know in some areas Restriction of Liberty Orders are very seldom used and in other areas they're used more frequently, and I think you also find if you look at the stats the areas that use them vary from time to time and that very much depends on the person, the attitude of the sentencer. So when I came here I think the number of RLOs increased... I know that after I left [place] the number of RLOs just dropped off a cliff and there are very few imposed" (Interview 16, sheriff).

Even some monitored people initiated conversations with us as researchers during our ethnographic observations of the work of field officers to infer they had knowledge and experience of which sheriffs and courts do and do not like EM.

In a city and court area that is anecdotally known to be resistant to the use of EM, which is reflected in statistics of lower use in that area, a criminal justice social worker speaks about how sheriffs do not regularly ask for suitability of EM to be assessed and the criminal justice social work team do not tend to recommend it:

\footnotetext{
"It's not used widely in [city]; I think we're one of the authorities that don't and again I think it's about courts as well... I'd asked a few social workers a couple of weeks ago about their use of it and they say they don't use it, they ask for it rarely and I was saying well why is that? I suppose there's a bit of a fixed thinking about this... they don't, and even if they do recommend it, sometimes sheriffs don't go for it" (Interview 10 , criminal justice social worker).
}

Another criminal justice social worker, in a different place and local authority, echoed this, speaking of 'quite a lot of resistance' and their occupational modus operandi as 'a lot of social workers will only consider it when the sheriffs kind of initiate an assessment' (Interview 4, criminal justice social worker). The narratives in their interview demonstrate that their current resistance to EM is rooted in its master status as a stand-alone punishment, and their occupational and individual ethic of care is more welfarist in prioritising supervision and rehabilitative supports. In other words, they do not categorically reject EM, but they do not 
like its privatised nature as it is outwith the remit of their work and they do not support its use in stand-alone forms that do not involve them.

These insights show that, at the pre-sentence stage, even the use of nationally standardised reporting templates and assessment processes may be mediated by the influence of localism and the professional ideologies of those involved, especially their stance towards EM and their awareness of the stance of those they work with. In 2015 and 2016, some participants in this study report ongoing local variations in consistency of use of national reporting templates in cases where electronic monitoring is being considered. Sometimes entirely different documents are used to assess suitability for a court-imposed EM order, in some cases depending on the behest of the sheriff and criminal justice social work team involved. For example, a criminal justice social worker described distinctions in sheriff stances to EM and whether they want a 'full assessment' along with the pre-sentence CJSW report: 'there has been a couple of sheriffs that are very keen on electronic monitoring on wanting the full assessment along with the criminal justice social work report and other sheriffs that aren't so keen' (Interview 17, criminal justice social worker). We are not claiming that this is necessarily widespread, but we, and participants in this study, can assert that it is known to occur. While this problematises notions of a 'Scottish approach', it is not necessarily perceived as problematic by criminal justice actors in the field.

Such localised differences mediated by professional ideologies and culturally conditioned working relationships are not necessarily unique to electronic monitoring. It fits within a more widely observed pattern in Scottish justice. Research by Tata and colleagues (2008: 841) revealed a common view among Scottish sheriffs in their study that criminal justice social workers, as pre-sentence report writers, were 'expected to gain knowledge of sentencing patterns in their particular court and to write reports accordingly.' The assistance and advice provided by criminal justice social workers in providing an assessment of sentencing options is conditioned by their knowledges and experiences of the sentencer as decision-maker, in ways which extend beyond any given national EM policy guidance. This, in part, relates to professional power differences. As decision-makers about the imposition and the management and completion of EM orders, sheriffs are categorically more powerful than criminal justice social workers, who are only asked to assess (if that) and have no supervision or further say in current stand-alone uses of EM.

Nellis (2016a: 182) summarises this pattern by observing that 'sheriffs have been rather variable in their use of EM, as with so many other forms of community supervision, and as geographical inconsistency in sentencing is not commonly perceived as a problem in Scotland, there are no easy judicial or political remedies for this.' Given its status as a mechanism for diversion from custody as well as decarceration, we echo the critiques of 
others in raising questions of consistency and fairness about the level of variation in uses of EM (Mair and Nellis, 2013; Nellis, 2016a; McIvor and Graham, 2016b). Whether a person is tagged or sentenced to prison should not significantly depend on where they live and who sentenced and assessed them.

\section{Reflections on the future: Moving from stand-alone uses towards a more integrated approach, with more EM modalities and technologies}

With regard to both court-imposed and prison-imposed EM orders, there is broad consensus among Scottish criminal justice actors in this study that in most but not all cases electronic monitoring should be integrated with supervision and support options. Participants maintain that there will continue to be some individuals who do not need concurrent supervision, but the expectation prevails that these will be a minority of cases. Furthermore, there is support across different participants for complementing or even shifting away from simple uses of Restriction of Liberty Orders (stand-alone EM ostensibly as an alternative to custody), to enable the option of EM to be added to Community Payback Orders (CPOs), which can include an offender supervision requirement as well as treatment requirements for alcohol, drugs or mental health. Community Payback Orders are used on a much larger scale than Restriction of Liberty Orders, with 19,016 CPOs imposed in 2014-2015 (Scottish Government, 2016b). One of the recommendations of this research is to introduce the option of supervision and support within Restriction of Liberty Orders, or introduce EM as an option to other community sentences and measures, e.g., CPOs. As already noted, the Scottish Government (2016a) have since announced plans to proceed on this basis.

Criminal justice social workers tend to emphasise that uses of EM should be integrated within a larger package or plan of supervision and risk management, as well as personalised support. Some of their narratives position EM as a kind of 'lesser evil' in directly comparing it to the other option of a short-term prison sentence.

"Electronic monitoring as part of a package within perhaps a Community Payback Order would be much, a much more suitable disposal than sending somebody to jail for three months or four months" (Interview 10 , criminal justice social worker).

This is unsurprising, especially where this concerns its use within the more frequently used Community Payback Orders, not just because of the evidence contrasting the impact of prison compared to community sentences but also because criminal justice social workers are the supervising officer for CPO's. 
This is where dualities in ideological stance start to emerge among criminal justice social workers. A few of them have expressed concerns about current stand-alone uses; however, they tend to become more optimistic in their envisioning of its future expansion and integration where this involves them. For example, one participant criticises their involvement being confined to pre-sentence assessments in the current approach, saying 'if it's a standalone order we would never be involved in it again and I think that's where the fundamental flaw is' (Interview 1, criminal justice social worker). Where criminal justice social worker discussions do appear to focus on a technology or modality - a chief example being broad support for introduction of the option of GPS tagging and tracking technology - the reasoning given quickly bifurcates into, foreseeably, an explicit desire to know where a monitored person is, with implications for monitoring and supervision but, equally, this seems to be accompanied by an implicit desire to be in the know. The implication of the latter is reinforcing or boosting their professional and occupational identity and discretionary power as supervisors and decision-makers in this area of the Scottish criminal justice field. In other words, the major statutory workers and institutions want EM configured in such a way that the private EM services provider, whom they tend to characterise as technicians, report to them so that they know what is going on and are in a position to influence decisionmaking and responses. This shifts their status and influence in relation to authorising agencies, namely sheriffs and courts, the Scottish Prison Service, and the Parole Board for Scotland.

In presenting this research to practitioners across the country, we have routinely used the old adage of criminal justice social workers feeling like 'prophets without honour in their hometown', feeling they have a wealth of practice wisdom to offer in community justice, yet being left out of the implementation of EM for over 15 years. Following an extensive process of in-depth consultation and recent indications that they will likely become supervising officers in most uses of EM, their narratives shift to include welcoming being given 'a place at the table.' This does not indicate a wholesale embracing of electronic monitoring, so much as a pragmatic assessment that EM is here to stay and that they have something to offer in pursuit of more ethical and effective uses of it.

\section{Concerns about future integration and expansion of electronic monitoring}

There are a few exceptions to the commonly held support of integration and advancement of EM, and such participants' resistance to the prospect of integration needs to be acknowledged, even though it represents a minority view. One participant forewarned that historical ideological opposition among Scottish social workers to the privatisation of 
punishment, in this case EM, may continue to influence the success of efforts to advance its integration with their work of offender supervision:

"I'm not sure how far we can go in terms of integration between the two particularly given that one of them's a private provider" (Interview 1, criminal justice social worker).

However, the very few participants seeming to be in favour of retaining the current standalone approach are Scottish sheriffs, one of whom spoke of a prior option of integration of 'electronic monitoring combined with probation supervision' as something they found 'was hopeless' (Interview 18, sheriff). They justified this stance on the grounds of not wanting to relinquish discretionary authority to criminal justice social workers to enforce compliance, expressing distrust and frustration with them as 'usurping their authority' by allowing instances of non-compliance and delaying breach proceedings; ostensibly, they saw criminal justice social workers as being too soft in 'working away with the person as social workers do' (Interview 18, sheriff).

Conversely, another sheriff (Interview 16) welcomed the prospect of integration, spoke of positive and productive current working relationships with criminal justice social workers in the different court areas they had worked in and stated that they wanted to integrate EM with Community Payback Orders, as they currently have to concurrently impose a Restriction of Liberty Order with a Community Payback Order to ensure that a monitored person gets supervision. In addition. nearly all sheriff participants supported the introduction of EM as an alternative to remand. They also referred to the importance of their judicial independence in articulating the critical view that they should decide which prisoners are granted Home Detention Curfews (early release with EM and a curfew on licence), which is currently decided in-house by Scottish Prison Service staff.

It seems that 'integrated' working is amenable to some Scottish sheriffs where it might afford them more authority to decide about the imposition and the completion or termination of EM orders in greater numbers, across modalities. The indication is one of accepting greater proximity that cooperation might bring, but resisting the need to engage in closer or more consultative collaboration in multi-agency work where that might affect their sense of independence and current hegemonic power in EM-related decision-making.

The underlying fulcrum of participants' discussions about the expansion and integration of EM is not one so much preoccupied with 'What Works?', so much as it is its potential impact on their work, their field of work and its reform. Integration implicates greater cooperation and more sharing of decision-making in daily mechanations of overseeing community justice in practice than currently exists with stand-alone uses of EM. Mooted changes to electronic monitoring in Scotland are framed by practitioner participants in ways which, we argue, are 
rooted in deeper matters of credibility, power, occupational identity and professional discretion - especially among those employed in statutory/public service roles. Who knows what, who does what, who gets what, and who decides are upheld as meaningful concerns.

\section{Conclusion}

There remains an acute need to reduce Scotland's comparatively high prison population, and making better uses of electronic monitoring within community sentences offers one way of trying to do this. However, EM is not the only option in pursuit of diversion and decarceration and its use must be proportionate and not in isolation, or it risks being overshadowed by the spectre of net-widening and up-tariffing. Further data and research on this is needed in Scotland, particularly given that previous attempts at penal innovation in this jurisdiction (as in others) have typically resulted in the expansion of community supervision without an attendant reduction in the numbers of individuals in custody (which have demonstrated an apparently inexorable rise) (see McNeill, 2016; Robinson and McNeill, 2016).

As we have elsewhere concluded from an international review of the uses of electronic monitoring (Graham and McIvor, 2015), the EM programmes and approaches which are shown to reduce reoffending during and/or after the monitored period are mostly those which include other supervision and supportive factors (e.g., employment and education, social capital) associated with desistance. While the evidence remains somewhat mixed, more effective approaches are found to be predicated upon high levels of integration with supervision and support from probation officers and other staff and services. In other words, the more effective programmes and approaches, in Europe in particular, are those where EM is not a stand-alone measure.

Our analysis here demonstrates that Scottish practitioners want integration in principle, but their support for it may depend on how and by whom this is done in practice and a resulting positive impact on the use of imprisonment cannot be guaranteed especially if the greater appeal of a more 'rehabilitative' form of EM results in it being used not just as an alternative to custody or as a mechanism for decarceration but as a sentence in its own right. There is also a risk that the more intensive penal scrutiny occasioned by the integration of monitoring and supervision may result in relatively high levels of breach as decision-makers seek to retain control not only over how EM is used, but also bow enforcement is managed.

We argue that practitioner and decision-maker perspectives on advancing electronic monitoring are tinged by influences of professional ideologies and localised cultures, as well 
as related concerns about their own professional identity and power, relative to other actors they work with in the Scottish criminal justice field. Although emergent and exploratory in nature, this article represents one of the first times such empirical findings and arguments have been demonstrated with regard to electronic monitoring as a feature of community justice in Scotland. However, the findings presented here affirm and further empirically illustrate what others have observed in Scottish criminal justice (see Halliday et al., 2009; Nellis, 2016a, 2016b).

One of the main implications is that the issues and complex contrasts found in this research may be accentuated within more integrated and flexible uses of EM in the future, making the discernment of a 'Scottish approach' to EM even more abstruse because of the extent of contingency on localised working relationships and ideological preferences between actors. Two of the factors contributing to a modicum of consistency in the current approach is the fact that EM is stand-alone and the fact that its implementation is overseen and prescribed by one national contract with one private EM service provider. At the time of writing, Scottish Government (2016a) plans indicate that the former will change and the latter is very possibly open to changing in the future. In light of this, we underscore the need for more discussions in policy and practice, and more independent research about perceptions and protections of proportionality and consistency in the uses of EM, including understanding the positive benefits as well as the potentially precarious and inequitable risks of localism. More integration may mean that more monitored people and practitioners experience EM increasingly differently or, if mechanisms are devised and supported to develop a more coherent national approach, integration may instead be a vehicle for consistent, ethical and effective uses occurring within local multi-agency working arrangements.

More data about the effectiveness of electronic monitoring is needed as a matter of critical urgency. Importantly, we argue that this needs to be accompanied by more empirical studies of the institutional and professional influences on practice and experience because, as shown here, consideration of work contexts, professional ideologies and cultures is valuable. Context matters and the uses of electronic monitoring do not occur in a vacuum. All practitioners involved in the uses of EM are not equal, nor do they divorce what they do with a given modality or technology from their practice values, practice wisdom and their standpoint in the criminal justice field. In summary, these Scottish jurisdictional findings as well as the broader European comparative findings highlight the need for more in-depth context-sensitive analysis of what affects the uses of electronic monitoring, with a view to better understanding and advancing more effective and ethical uses of EM in the future.

\section{Funding acknowledgement}


${ }^{1}$ This research project 'Creativity and effectiveness in the use of electronic monitoring as an alternative to imprisonment in EU member states' (Hucklesby, Beyens, Boone, Dünkel, McIvor and Graham, 2016) and various research-related resources (http://emeu.leeds.ac.uk/reports/) have been produced with the financial support of the Criminal Justice Programme of the European Commission (JUST/2013/JPEN/AG/4510). The contents are the sole responsibility of the authors and can in no way be taken to reflect the views of the European Commission.

\section{References}

Armstrong, S., Malloch, M., Nellis, M., \& Norris, P. (2011) Evaluating the Effectiveness of Home Detention Curfew and Open Prison in Scotland, Edinburgh: Scottish Government.

Barry, M., Malloch, M., Moodie, K., Nellis, M., Knapp, M., Romeo, R., \& Dhanasiri, S. (2007) An Evaluation of Use of Electronic Monitoring as a Condition of Bail in Scotland, Edinburgh: Scottish Executive Social Research.

Electronic Monitoring Working Group [Scotland] (2016) Electronic Monitoring in Scotland Working Group Final Report, Edinburgh: Scottish Government. Available online at: http://www.gov.scot/Publications/2016/10/8620 (Accessed 5/10/2016).

Fawcett, J., Costley, N., \& Granville, S. (2014) Development of Electronic Monitoring in Scotland: Analysis of Consultation Responses, Edinburgh: Scottish Government Social Research.

G4S (2016) Electronic Monitoring to the Criminal and Youth Justice Systems in Scotland: Statistical Bulletin 1 January 2015 - 31 December 2015 Glasgow: G4S.

Graham, H. (2016) Rehabilitation Work: Supporting Desistance and Recovery, London: Routledge.

Graham, H., \& McIvor, G. (2015) Scottish and International Review of the Uses of Electronic Monitoring Stirling: Scottish Centre for Crime and Justice Research [SCCJR], University of Stirling.

Graham, H., \& McIvor, G. (2016) 'The Influences of Electronic Monitoring in the Desistance Process: Practitioner and Decision-Maker Perspectives' Scottish Journal of Criminal Justice Studies 22: 5-17 [open access], Glasgow: Scottish Association for the Study of Offending (SASO). Available online (Accessed 20/01/2017): http://www.sastudyoffending.org.uk/attachments/article/171/SASO $\% 20 \mathrm{Journal} \% 2$ 02016\%20.pdf

Halliday, S., Burns, N., Hutton, N., McNeill, F., \& Tata, C. (2009) 'Street-Level Bureaucracy, Interprofessional Relations, and Coping Mechanisms: A Study of Criminal Justice Social Workers in the Sentencing Process' Law \& Policy 31(4): 405-428.

Hucklesby, A. (2011) 'The Working Life of Electronic Monitoring Officers' Criminology \& Criminal Justice, 11(1): 59-76. 
Hucklesby, A., Beyens, K., Boone, M., Dünkel, F., McIvor, G., \& Graham, H. (2016a) Creativity and Effectiveness in the Use of Electronic Monitoring: A Case Study of Five Jurisdictions [comparative report], Leeds: University of Leeds and Criminal Justice Programme of the European Commission.

Hucklesby, A., Beyens, K., Boone, M., Dünkel, F., McIvor, G., \& Graham, H. (2016b) 'Creativity and Effectiveness in the Use of Electronic Monitoring: A Case Study of Five European Jurisdictions’ Journal of Offender Monitoring, 27(2), pages 5-29.

Hucklesby, A., \& Holdsworth, E. (2016) Electronic Monitoring in England \& Wales research report, Leeds: Criminal Justice Programme of the European Commission and the University of Leeds.

Hutton, N., \& Tata, C. (1995) Patterns of Custodial Sentencing in the Sheriff Court, Edinburgh: The Scottish Office Central Research Unit.

Jamieson, F. (2013) 'Narratives of Crime and Punishment: A Study of Scottish Judicial Culture' Unpublished PhD dissertation, Edinburgh: University of Edinburgh.

Mair, G., \& Nellis, M. (2013) 'Parallel Tracks': Probation and Electronic Monitoring in England, Wales and Scotland' in Nellis, M., Beyens, K., \& Kaminski, D. (eds.) Electronically Monitored Punishment: International and Critical Perspectives, London: Routledge.

Matheson, M. (2015) Fairer Justice: A Vision for Scotland - Apex Annual Lecture 2015, Edinburgh: Apex Scotland.

McAra, L. (2008) 'Crime, Criminology and Criminal Justice in Scotland' European Journal of Criminology 5(4): 481-504.

McIvor, G., \& Graham, H. (2016a) Electronic Monitoring in Scotland research briefing paper, Stirling: Criminal Justice Programme of the European Commission and the University of Stirling.

McIvor, G., \& Graham, H. (2016b) Electronic Monitoring in Scotland research report, Stirling: Criminal Justice Programme of the European Commission and the University of Stirling.

McNeill, F. (2016) 'Reductionism, Rehabilitation and Reparation: Community Punishment in Scotland' in Robinson, G., and McNeill, F. (eds.) Community Punishment: European Perspectives, London: Routledge.

Millie, A., Tombs, J., \& Hough, M. (2007) 'Borderline Sentencing: A Comparison of Sentencers' Decision-making in England and Wales, and Scotland' Criminology \& Criminal Justice 7(3): 243-267.

Nellis, M. (2006) 'Electronically Monitoring Offenders in Scotland, 1998-2006' The Scottish Journal of Criminal Justice Studies, 12: 74-96. 
Nellis, M. (2007) 'Press Coverage of Electronic Monitoring and Bail in Scotland', in M. Barry, M. Malloch, K. Moodie, M. Nellis, M. Knapp, R. Romeo, \& S. Dhanasiri (2007) An Evaluation of the Use of Electronic Monitoring as a Condition of Bail in Scotland, Edinburgh: Scottish Executive Social Research.

Nellis, M. (2009) 'Surveillance and Confinement: Explaining and Understanding the Experience of Electronically Monitored Curfews' European Journal of Probation 1(1): 4165.

Nellis, M. (2014) 'Penal Innovation and the Imaginative Neglect of Electronic Monitoring in Scotland' The Scottish Journal of Criminal Justice Studies 20: 14-38.

Nellis, M. (2015) Standards and Ethics in Electronic Monitoring Report, Strasbourg: Multilateral Meeting on Electronic Monitoring, Recommendations of the Committee of Ministers of the Council of Europe CM/Rec (2014)4, Council of Europe.

Nellis, M. (2016a) 'The Strategic Failure of Electronic Monitoring in Scotland' in Croall, H., Mooney, G., \& Munro, M. (eds.) Crime, Justice and Society in Scotland London: Routledge.

Nellis, M. (2016b) 'Using EM Requirements in the Context of a Community Sentence: Some Propositions for CJSWs' paper presented at The Future of Electronic Monitoring in Scotland, hosted by Scottish Government Community Justice in Paisley, Scotland on $19^{\text {th }}$ January 2016.

Nellis, M. (2016c) 'Electronic Monitoring and Penal Reform: Constructive Resistance in the Age of "Coercive Connectedness" British Journal of Community Justice 14(1): 113-132.

Paterson, C. (2007) 'Street-level Surveillance': Human Agency and the Electronic Monitoring of Offenders' Surveillance \& Society, 4(4): 314-328.

Platts, A., and Waterton, J. (2016) Consultation on Proposals to Strengthen the Presumption against Short Periods of Imprisonment: An Analysis of Responses, Edinburgh: Scottish Government Social Research.

Robinson, G., \& McNeill, F. (eds.) (2016) Community Punishment: European Perspectives, London: Routledge.

Rudes, D., Viglione, J., \& Taxman, F. (2014) 'Professional Ideologies in United States Probation and Parole' in Durnescu, I., \& McNeill, F. (eds.) Understanding Penal Practice, London: Routledge.

Scottish Government (2013) Development of Electronic Monitoring in Scotland: A Consultation on the Future Direction of the Electronic Monitoring Service, Edinburgh: Scottish Government.

Scottish Government (2015) Reconviction Rates in Scotland: 2012-2013 Offender Cohort Statistical Bulletin, Edinburgh: Scottish Government.

Scottish Government (2016a) 'Expanding Tagging Sentences: Increased Monitoring, Greater Support and New Technologies Tested' 
http://news.scotland.gov.uk/News/Expanding-tagging-sentences-2c5a.aspx (Accessed 5/10/2016).

Scottish Government (2016b) Criminal Justice Social Work Statistics in Scotland: 2014-2015, Edinburgh: Scottish Government. Available online at http://www.gov.scot/Resource/0049/00497837.pdf (Accessed 10/10/2016).

Scottish Prison Service (2016) 'SPS Prison Population', http://www.sps.gov.uk/Corporate/Information/SPSPopulation.aspx Accessed 19/09/2016).

Smith, G. (2012) 'Surveillance Work(ers)' in Ball, K., Haggerty, K., \& Lyon, D. (eds.) Routledge Handbook of Surveillance Studies, London: Routledge.

Tata., C., Burns, N., Halliday, S., Hutton, N., \& McNeill, F. (2008) 'Advising and assisting the sentencing decision process: The pursuit of 'quality' in pre-sentence reports' British Journal of Criminology 48(6); 835-855.

Tombs, J., \& Jagger, E. (2006) 'Denying Responsibility: Sentencers' Accounts of their Decisions to Imprison’ British Journal of Criminology 46(5): 802-831.

World Prison Brief (2016) 'United Kingdom: Scotland' (figures as at August 2016) http://www.prisonstudies.org/country/united-kingdom-scotland

(Accessed 19/09/2016). 